\title{
Coarctation of the Aorta in the Adult
}

Authors: Harald Kaemmerer, Alfred Hager and John Hess

Department for Paediatric Cardiology and Congenital Heart Disease, Deutsches Herzzentrum München

Address for correspondence:

Prof. Dr. Dr. Harald Kaemmerer

Department for Paediatric Cardiology and Congenital Heart Disease

Deutsches Herzzentrum München

Lazarettstr. 36

D-80636 München

Germany

\section{Email:}

Kaemmerer@dhm.mhn.de

ABSTRACT Coarctation of the aorta is a complex systemic cardiovascular disease.The most prominent feature is the stenosis at the aortic isthmus that can be removed surgically or by catheter intervention. However, there are often concomitant cardiovascular problems like a bicuspid aortic valve, vascular wall abnormalities, arterial hypertension and vascular aneurysms. Therefore, regular life-long medical follow-up is necessary including modern imaging techniques, even after successful primary treatment.

\section{DEFINITION / MORPHOLOGY /PATHOPHYSIOLOGY}

Coarctation of the Aorta (CoA) is, as part of a generalized arteriopathy, a complex cardiovascular disorder, and not only a circumscript narrowing of the aorta in the area where the ductus arteriosus inserts. ${ }^{(1,2)}$

In 1760 Morgagni described CoA, seen during the autopsy of a monk, and refers to a similar case reported by the elder Meckel in 1750.(3) More detailed patho-anatomical descriptions followed from Jordan (1827), Reynaud (1828) and others. ${ }^{(4)}$

In 1903 LM Bonnet ordered this lesion into infantile and adult types. The categorization was later revised to preductal and postductal forms.

The infantile type was characterized by a long, narrowed aortic segment, located proximal to the ductus, persistence of the ductus and death in early infancy, often due to congestive cardiac failure. The adult type was distinguished by a more circumscript, postductal narrowing of the aorta, accompanied by a closed ductus and clinical manifestation in later life.

This classification has been widely replaced and currently, in view of the pathogenesis, all types of CoA are esteemed to be "juxtaductal".
In adults CoA is almost always located just below the origin of the left subclavian artery at the conjunction of the distal aortic arch to the descending aorta. In rare cases CoA may be localized ectopically, anywhere in the ascending, descending or abdominal aorta.

The pathogenesis of CoA is still not completely understood; the "ductus tissue theory" and the "hemodynamic theory" have recently been proposed.

In the ductus tissue theory, postnatal constriction of aberrant ductal tissue and/or intrauterine alterations of blood flow through the aortic arch are incriminated as cause. Others have proposed that CoA develops from hemodynamic alteration that reduces the volume of blood flow through the fetal aortic arch and isthmus.

CoA is often seen in association with a bicuspid aortic valve, a subvalvular, valvular, or supravalvular aortic stenosis, hypoplastic left heart syndrome, mitral valve stenosis or complex congenital heart defects with one of those entities.

CoA may occur as either a localized stenosis or as a long and hypoplastic aortic segment. In the localized form, there is a shelf-like infolding of the posterior aortic wall into the aortic lumen, either opposite, proximal or distal to the ductus arteriosus.

The shelf consists of thickened aortic media and intima and is always in continuity with the muscular tissue of the ductus arteriosus. At times of ductal closure anomalous fibroductal tissue around the aorta tracks the shelf towards the ductal orifice, causing luminal obstruction.

Diffuse forms of CoA are characterized by a tubular hypoplasia involving the aortic arch or the aorta distal to the origin of the left subclavian artery and the ductus area.

CoA may occur as an isolated defect or combined with other important intracardiac and/or extracardiac lesions. Simple CoA refers to CoA in the absence of other relevant lesions. However, even simple CoA is often accompanied by anomalies, previously thought to be insignificant, like bicuspid aortic valve (up to $85 \%$ ), mitral valve anomalies, and/or intracranial aneurysms. Complex CoA refers to the association with other important lesions, e.g. ventricular septal defects and major mitral or aortic valve abnormalities. Sometimes, CoA complicates complex heart defects, such as transposition of the great arteries, Taussig-Bing anomaly, double-inlet left ventricle, tricuspid atresia with transposition of the great arteries, and hypoplastic left heart syndrome.The association 
of multiple left-sided obstructive lesions with coarctation is referred to as the Shone-complex. On the other hand, CoA is rarely associated with severe right ventricular outflow tract obstructions. CoA can also be associated with Turner's or William's syndrome, congenital rubella or neurofibromatosis, Takayasu aortitis or trauma.

The foremost clinical feature of CoA is arterial hypertension in the upper body and arms (prestenotic) and low blood pressure in the lower body and legs. This imposes significant afterload on the left ventricle, resulting in increased wall stress and compensatory left ventricular hypertrophy. Left ventricular systolic and diastolic dysfunction may develop secondary to elevated afterload and related to reduced ventricular compliance caused by left ventricular hypertrophy, increased interstitial fibrosis or myocardial mass.

An increasing afterload of the left ventricle induces the development of arterial collaterals, which bypass the CoA.

Arterial hypertension may develop due to the mechanical obstruction and/or may - at least in part - be caused by a diminished (post-stenotic) renal blood flow and a subsequent activation of the renin-angiotensinaldosterone system. An additive activation of the central sympathetic nervous system may also be responsible for hypertension.

In CoA patients early elastic fiber fragmentation, fibrosis and so-called "cystic medial necrosis" could be uncovered in the wall of the ascending and descending aorta. ${ }^{(2,5)}$ These wall abnormalities result in an increased stiffness of the $\operatorname{aorta}^{(6,7)}$ and of the carotid arteries, ${ }^{(8)}$ in a blunted baroreceptor reflex, ${ }^{(9)}$ in an increased brachial pulse wave velocity ${ }^{(10)}$ and may be related to late aneurysm formation or aortic dissection.

Aortic stiffness and increased pulse wave velocity are also present late after CoA repair. ${ }^{(8,10)}$ Furthermore, an increased carotid intima-media thickness was found in young adults ${ }^{(11,12)}$ and children ${ }^{(13)}$ with CoA, as well as a diminished endothelium dependent and independent vasodilatation in the right brachial artery. ${ }^{(10,13-15)}$

\section{EPIDEMIOLOGY AND GENETICS}

CoA is a relatively common type of congenital heart defect that accounts for $5-8 \%$ of all congenital heart defects.

The prevalence of isolated CoA is about 0.33 per 1000 live births. ${ }^{(16)}$ Series from Southeast Asian countries show lower incidence. ${ }^{(17)}$ In Japan, the reported incidence varied between 0.3-1.5\%. Ongley mentioned non-existence of CoA in Thailand. ${ }^{(18)}$

Besides sporadic cases, genetic influences are possible. CoA is more common in people with Turner's syndrome. Sporadically it is associated with William Beuren syndrome or Noonan syndrome. Furthermore, there are family clusters with a high prevalence of different left heart obstructive defects including CoA, bicuspid aortic valve, congenital valvular aortic stenosis, and hypoplastic left heart syndrome, $(19,20)$ suggesting an oligogenetic pattern of inheritance in those families.

Typical CoA is more common in white males than females, with a maleto-female ratio of $1.3-2.0$ : I.

\section{CLINICAL PRESENTATION}

Depending on the degree of stenosis and associated cardiovascular defects, significant, unrepaired CoA commonly causes problems already in early infancy.

According to historic series, $60 \%$ of untreated patients with symptomatic, high-grade CoA and $90 \%$ of patients with complicated CoA died within the first year of life. Of those who survived the first two years, 25\% died before age $20,50 \%$ before age $32,75 \%$ before age 46 , and $92 \%$ before age $60 .{ }^{(21)} \mathrm{A}$ few reports exist of patients living to 78,85 , or indeed 92 years of age. ${ }^{(22)}$

Untreated patients surviving into adulthood typically have milder forms of $\mathrm{CoA}$ and may remain asymptomatic and therefore undetected until adolescence or even adulthood.

Major problems in the natural course, possibly causing death, include left ventricular failure (28\%), intracranial hemorrhage (12\%), bacterial endocarditis (18\%), aortic rupture/dissection (21\%), premature coronary artery disease, and associated heart defects. ${ }^{(23)}$

\section{Medical history and physical findings in Coarctation}

Signs and symptoms of CoA depend on the severity of the disorder. Serious CoA is likely to exhibit signs and symptoms early in life, while mild cases may not become evident until adulthood.

Adults have a tendency to have milder CoA with significant collaterals and therefore often have no or mild symptoms. Adult patients often present with arterial hypertension or a murmur.

Key symptoms are headache, nosebleeds, dizziness, tinnitus, shortness of breath - especially during exercise - abdominal angina, leg cramps, exertional leg fatigue, cold feet, and even intracranial hemorrhage attributed to upper body arterial hypertension.

Cardinal clinical features include upper body hypertension, lower body hypotension, diminished, delayed femoral pulses, a blood pressure decrease between upper and lower extremities, and palpable collateral arteries running over the medial aspects of the scapulae, the lateral chest wall, and between the ribs. 
Clinical diagnosis is based on simultaneous palpation of brachial and femoral pulses and blood pressure measurement on all extremities. Usually the systolic blood pressure in the lower extremities should be 5 - $10 \mathrm{mmHg}$ higher compared with the upper extremities. ${ }^{(24)} \mathrm{A}$ blood pressure difference of more than $20 \mathrm{~mm} \mathrm{Hg}$ in favor of the arms may be indicative of COA.

A diminished left brachial pulse suggests an anomalous origin of the left subclavian artery below the coarctation site or a stenosis, a weak right brachial pulse an aberrant, distally displaced origin of the right subclavian artery.

Other physical findings include a thrill in the suprasternal notch or the neck vessels, and a heaving but not displaced apex beat.

On auscultation the aortic closure sound is loud. Patients with a bicuspid aortic valve or an aortic aneurysm have an early systolic ejection click. An additional systolic ejection murmur transmitted to the carotids may be found in the 2nd parasternal intercostal space in CoA patients with a bicuspid aortic valve or arterial hypertension.

Between the scapulae, a vascular murmur may be heard that is separated from the first heart sound and lasts beyond the second heart sound.

Collateral vessels may additionally be audible as continuous murmurs.

Electrocardiography may show varying degrees of left atrial and left ventricular (LV) pressure load and signs of LV ischemia or strain.

The chest $\mathrm{X}$-ray may show an ectatic ascending aorta, kinking or double contouring in the region of the descending aorta ("figure-3"-sign), and widening of the soft-tissue shadow of the left subclavian artery.

Rib notching at the postero-inferior borders of the 3rd and 4th (to 8th) ribs, secondary to intercostal collaterals, is often seen in adults.

Transthoracic echocardiography may provide important information regarding site, structure, and extent of the stenosis as well as systolic and diastolic left ventricular function and hypertrophy, associated cardiac abnormalities, aortic diameters, and supraaortic vessels.

Unfortunately the aortic isthmus itself is often not readily detectable in adults, as the proximity of the left bronchus frequently causes artifact superimposition. Doppler studies may show a turbulent flow pattern with a diastolic "run-off"--phenomenon and increased systolic flow rates distal to the coarctation.

The Bernoulli equation, estimating the gradient from the peak systolic blood flow velocity, is only validated for valve stenosis and may overestimate CoA, especially in a stiff tubular structure with an enhanced pulse wave velocity. In CoA the flow rates proximal to and within the stenosis have to be taken into account to avoid an overestimation of the pressure gradient. If the proximal flow rate is $>1.0 \mathrm{~m} / \mathrm{sec}$, the expanded Bernoulli equation $\left(\Delta \mathrm{p}=4\left(\mathrm{~V}_{2}^{2}-\mathrm{V}_{1}^{2}\right)\right)$ will have to be used. ${ }^{(25)}$

Comparison of catheter derived gradients with gradients derived by Doppler echocardiographic maximum and mean velocity is problematic However, a resting peak systolic velocity of $\geq 3,2 \mathrm{~m} / \mathrm{s}$ and a diastolic velocity of $\geq 1,0 \mathrm{~m} / \mathrm{s}$ may be suggestive of significant coarctation.

In the presence of an extensive bypassing collateral network, the systolic and diastolic gradients are not very reliable. Also, after surgica coarctation repair a gradient may develop even in the absence of significant narrowing due to a lack of aortic compliance.

Recent Doppler studies indicate that differentiation between restenosis and enhanced aortic stiffness can be performed by analyzing diastolic flow patterns at the isthmus (Figure I). A pan-diastolic run-off is the most important echocardiography sign of restenosis. ${ }^{(26)}$

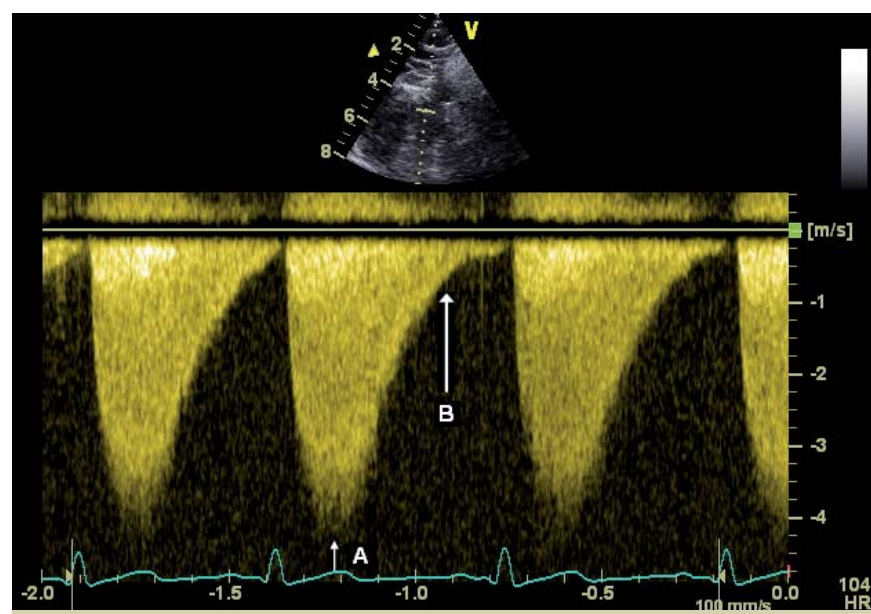

FIGURE 1: Continuous wave Doppler flow velocity at the aortic coarctation site indicating a restenosis: The peak velocity $(\mathrm{A})$ can not differentiate between restenosis and enhanced aortic stiffness. However, the pan-diastolic run-off (B) is the more specific echocardiography sign of restenosis (with courtesy to J. Schoetzau)

The role of transesophageal echocardiography is a minor one in adults because the quality of aortic isthmus imaging tends to be poor.

Intravascular ultrasound may give additional information regarding restenosis, local aneurysm formation or intramural hematoma. However, non-invasive imaging techniques with similar resolution are available and, therefore, preferred today. 
Magnetic resonance imaging (MRI) and computed tomography (CT) are the favorite noninvasive techniques to evaluate $\mathrm{CoA}$ or re-CoA in adults. Both methods depict site, extent and degree of the aortic narrowing, the aortic arch, the pre- and post-stenotic aorta, and the collateral vessels, if present. Moreover, modern MRI methods even provide an estimation of blood flow and pressure gradients across the stenosis, and provide information on the collateral flow. ${ }^{(27)}$

Likewise, it is of utmost importance to reliably detect complications related to the natural history or to therapeutic procedures, e.g. aneurysm of the ascending aorta or at the site of previous surgery or intervention, aortic dissections, re- or residual stenosis or a hypoplastic aortic arch. The course and patency of prosthetic bypasses can also be detected.

Cardiac catheterization may not be required. Manometry and angiocardiography delineate the anatomy of the entire aorta and the supraaortic vessels, the degree of hypoplasia of the transverse aortic arch, the extent of collaterals, determine the pressure gradient across the coarctation, detect associated heart defects and evaluate left ventricular function and coronary status, particularly when other imaging modalities findings are not indicative.

At catheterization a significant CoA with a peak-to-peak gradient of $>$ $20 \mathrm{~mm} \mathrm{Hg}$ across the CoA is indicative of significant obstruction in the absence of a well-developed collateral circulation. However, the gradient depends on not only the extent of aortic narrowing but also the size and number of collateral vessels and cardiac output. If there is extensive collateral circulation, there may be minimal or no pressure gradients, even in high-grade CoA.

Due to the increased risk of premature coronary artery disease, coronary angiography is important in patients with coronary risk factors and in patients older than 40 years.
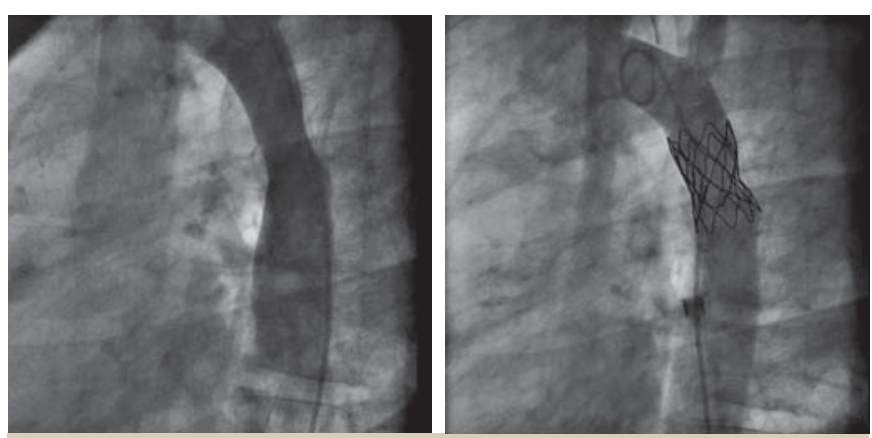

FIGURE 2: Stent implantation in a 16-year-old patient with restenosis after coarctation repair with end-to-end anastomosis at the age of 11 months. Stent implantation reduced the invasively measured systolic gradient from $25 \mathrm{mmHg}$ to $-1 \mathrm{mmHg}$.

\section{Interventional and surgical treatment}

Treatment options for CoA depend on age at time of diagnosis, the degree of stenosis, and the type of associated cardiac defects.

Balloon angioplasty for aortic CoA has been available since 1982. This procedure enlarges the size of the narrowed segment, lowers the pressure gradient and diminishes collateral vessels.

Even if CoA can primarily be released by balloon angioplasty, the aortic diameter may decline due to the elastic recoil of the aortic wall. Such recoil can be avoided with implantation of endovascular stents (Figure 2), which have been available for CoA since 1991.(28) Main indications for balloon-expandable or self-expandable stents are currently long-segment coarctation, associated hypoplasia of the isthmus or aortic arch, tortuous CoA with malalignment of the proximal and distal aortic segment, and recurrent aortic CoA or an aneurysm following prior surgical or balloon therapy. ${ }^{(29,30)}$

Experience with covered stents in highly selected patients with a postangioplasty aneurysm, tortuous aortic arch and isthmus, associated patent ductus arteriosus, and extremely narrow $\mathrm{CoA}$ is limited. ${ }^{(30)}$ Biodegradable stents are under development.

In conclusion, in experienced centers angioplasty with or without stent implantation has become an effective and safe treatment option for children and adults with re- or residual CoA after prior surgery, although long-term follow-up studies are lacking.(31,32) Although most frequently used in neonates, infants and children, it can also be used in adults. ${ }^{(33)}$ In principle, this procedure may also be indicated in uncomplicated native aortic coarctation, but the point is controversial.

Surgical relief of the stenosis was introduced more than 60 years ago.(34-36) Since 1944 a lot of different operative techniques for the surgical removal of CoA have been designed. ${ }^{(37)}$ The most important ones are resection and end-to-end anastomosis, resection and extended end-to-end anastomosis, prosthetic patch aortoplasty, subclavian flap aortoplasty, interposition of a (tube) graft, bypass tube (jump) grafts, etc. They all have specific advantages, disadvantages and long-term problems.

The selection of procedure depends on the nature, site and extent of the coarctation, and on the patient's age.

CoA repair in adolescents or adults is usually undertaken electively. There is a tendency to operate as early as possible after diagnosis to minimize late mortality and morbidity. However, the age-related risks and rate of complications have to be taken into account. 
Due to a low surgical risk, the best age for elective surgery has proved to be 2 - 5 years. In this age group the aortic diameter is usually larger than half the anticipated adult size, reducing the risk of relevant residual stenosis after operation. However, at the same time sequelae from hypertension, progressive left ventricular hypertrophy and/or dysfunction may increase. Beyond age six arterial hypertension often persists.

Older children and adults are operated on soon after diagnosis. The operative mortality is high in neonates and infants, and low in older children. Beyond age 30 or 40 , intraoperative mortality increases as a consequence of degenerative aortic wall changes, coexisting bicuspid aortic valve disease, mitral valve abnormalities, coronary artery disease, and end-organ damage from systemic arterial hypertension.

A survey of I I major studies which include 2355 patients operated on between 1946 and 1994, showed an acute mortality between 3\% and $32 \%$, which was strongly correlated with the complexity of associated lesions. ${ }^{(38)}$ Today, the surgical risk in simple CoA is less than $1 \%$.

All in all, there is an ongoing discussion about the optimal treatment strategy. Few randomized studies with short- and mid-term follow-up showed the advantages of surgical techniques over balloon dilatation in primary treatment. ${ }^{(39)}$ However, comparative data regarding stent implantation are still missing.

\section{MEDICAL INTERVENTION}

Patients without a significant residual systolic gradient, with normal blood pressure at rest and exercise, can do without restrictions on physical activity.

As longstanding arterial hypertension increases the risk of coronary artery disease, cholesterol levels should be controlled and regulated, obesity and smoking be avoided.

Medical treatment is usually used to control blood pressure before and after surgery. Long-term postoperative hypertension can be treated primarily with betablockers, vasodilators (ACE inhibitors, AT-II antagonists) or diuretics. However, it has to be kept in mind that ACEinhibitors or AT-II antagonists may have adverse effects in CoA if residual arch obstruction or re-CoA exists. To get these patients "normotensive" may cause an inadequate lower-body perfusion and may produce renal failure. Medical drug treatment often fails to achieve normotension, if a significant restenosis is present.

In the early postoperative and post-interventional course of CoA treatment sometimes a post-coarctation syndrome can be seen. This paradoxical hypertension is caused by a delay in the reset of the baroreceptor reflex mainly in the first 2- 14 days after coarctation repair Clinically, it consists of a severe arterial hypertension that can progress to a disastrous mesenteric arteritis. Early and aggressive antihypertensive treatment is necessary. Periprocedural prophylaxis with betablockers has shown to be effective. ${ }^{(40,41)}$

\section{LATE OUTCOME}

\section{Survival and functional status}

Surgery improves, at least in the short term, clinical symptoms, blood pressure and also survival while, because of cardiovascular complications and arterial hypertension, long-term mortality is still higher than in the general population. ${ }^{(42,43)}$

In a Mayo Clinic follow-up study, including 646 patients with a simple CoA, operated on between 1946 and 1981, the postoperative 10-year survival was $91 \%$, 20-year survival was $84 \%$, and 30 -year survival $72 \% .{ }^{(44)}$ In this series, 87 cases of late death occurred in the long-term follow-up among 57I patients. The mean age at death was 38 years, commonly attributed to coronary artery disease, sudden cardiac death, left ventricular failure, cerebrovascular accidents and ruptured aortic aneurysm. ${ }^{(44)}$

Exercise capacity is slightly compromised, but far less than in other congenital heart defects. ${ }^{(45)}$

\section{Residua, sequelae and complications in the long term}

The most eminent residua, sequelae and complications are arteria hypertension, re- or residual coarctation, and aneurysms of the ascending aorta or at the site of intervention.

Additional problems may arise from a bicuspid aortic valve, anomalies of the mitral valve, coronary artery disease, infective endocarditis or cerebral vascular anomalies.

\section{Arterial hypertension}

Arterial hypertension, either at rest or during exercise, is common, even after successful treatment of aortic CoA, despite the absence of any residual coarctation. ${ }^{24,46,47)}$ In a recent study, even $30 \%$ of those patients without restenosis and without prosthetic material are hypertensive. ${ }^{(48)}$ This is an important risk factor for increased mortality. Particularly patients who underwent CoA repair a long time ago or at an older age, are threatened for an abnormal blood pressure response. ${ }^{(49)}$ The older the patient at the time of CoA repair, the higher the postoperative incidence of arterial hypertension. ${ }^{(44)}$ Patients operated on between the ages of 2 and 9 , more frequently have a normal blood pressure later in life. Several studies after CoA repair also suggest a rising prevalence of arterial hypertension with increasing length of follow-up: I $3 \%$ at 8 years, $49 \%$ at 17 years, and $68 \%$ at 30 years. ${ }^{(38)}$ 
In coarctation patients, hypertension is probably correlated to residual or recurrent coarctation, structural changes in the arterial wall of peripheral and central vessels, alteration of arterial compliance, a hypoplastic aortic arch, abnormal vascular vasoreactivity, abnormal baroreceptor sensitivity, alterations in the renin-angiotensin-system, elevated plasma-epinephrine and -norepinephrine levels, or coexistence of essential arterial hypertension.

Hypertensive patients are at risk for premature coronary artery disease, ventricular dysfunction, and rupture of aortic or cerebral aneurysms, particularly if they reach their 3rd or 4th decade of life.

The impact of isolated, exercise-induced hypertension, not rarely seen in these patients, is still a matter of debate. ${ }^{(49-51)}$

\section{Re- or residual coarctation}

Re- or residual stenosis at the site of coarctation, defined as a peak-topeak systole pressure gradient in excess of $20 \mathrm{~mm} \mathrm{Hg}$ with or without angiographically demonstrable narrowing,(30) is an important cause of morbidity after CoA treatment, as it may induce or aggravate systemic arterial hypertension, left ventricular wall mass, coronary artery disease and/or congestive heart failure.

Recoarctation or residual stenosis may occur with all known surgical techniques and amounts to $3 \%$ to $41 \%{ }^{(38,52)}$ No single technique appears to be superior to the others, but is particularly associated with smaller patient size, younger age at operation, and the presence of associated transverse aortic arch hypoplasia. Moreover, era of operation, surgical technique and duration of follow-up further influence the risk.

Children operated on in infancy are at particular risk. In this group the incidence of residual and re-stenosis is at 20-38\%, in patients older than 3 years only about $1.5 \%$.

Re-CoA is also an essential concern after angioplasty. In native adult CoA 8- I I\% of patients develop restenosis. For re-CoA after preceding surgical repair, several large angioplasty series demonstrate an early success rate (pressure gradient $<20 \mathrm{~mm} \mathrm{Hg}$ ) between 65\% and $100 \% .{ }^{(38)}$ Yetman et al. could demonstrate that $72 \%$ of patients with optimal immediate results did not require reintervention within the following 12 years. ${ }^{(53)}$

Angioplasty of CoA may be ineffective because of elastic recoil, long segment narrowing, or multiple serial obstructions. Under such circumstances balloon-expandable stents are effective and safe, at least in the short and medium term. If necessary, re-expansion of the stent to treat re-/residual CoA is efficient.
Aneurysms of the ascending aorta or in the region of the aortic isthmus

Aneurysms of the ascending aorta or in the region of the aortic isthmus have the risk of life-threatening rupture. In several postoperative followup studies cases of late deaths are included, which were related to aortic dissection, particularly in the ascending aorta.

The reasons for aneurysm formation in the ascending aorta (Figure 3) are not yet fully understood, but bicuspid aortic valves, independent aortic wall changes, and/or arterial hypertension may be responsible. ${ }^{(2)}$

All types of surgery carry the risk of aneurysm formation. The risk depends on the era of the operation, the patient's age at the time of surgery, the postoperative interval and on the surgical technique employed.

Recent studies show aortic aneurysms in only 5-9\% of patients, ${ }^{(54)}$ while older studies after Dacron-patch aortoplasty reported aneurysm formation in up to $33 \%$ or even $51 \%$. The lowest incidence is described after end-to-end anastomosis or after extraanatomic tube grafts.

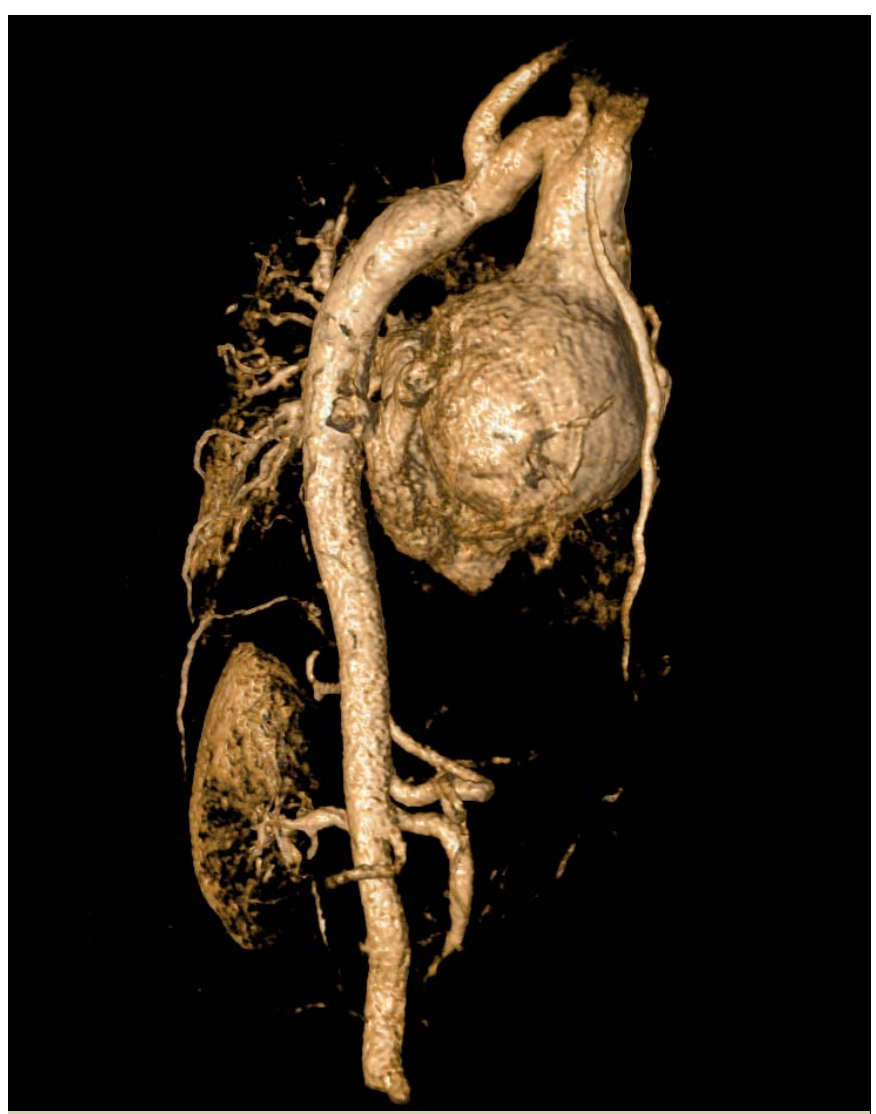

FIGURE 3: Magnetic resonance image with contrast media in volume rendering technique depicting an aneurysm of the aortic valve sinus with a diameter of $83 \mathrm{~mm}$ in a 49 -year-old patient 39 years after coarctation repair with end-to-end anastomosis. Echocardiography revealed a bicuspid aortic valve with moderate aortic regurgitation. The patient underwent Bentall's operation implanting a mechanical aortic valve and an ascending aortic tube graft (with courtesy to S. Fratz). 
Whether and when postoperative aneurysms appear cannot be predicted. Many aneurysms are detected as an incidental finding because their development rarely produces symptoms. Some aneurysms have been found $>30$ years after surgery.

Aneurysms may also occur immediately or several months after balloon angioplasty of either native or operated CoA and may be caused by the injury to the endovascular layers during treatment and related to medial changes in the pre- and post-CoA segments. ${ }^{(30)}$ On the other hand, even major iatrogenic tears may decrease and disappear without aneurysm formation.

The reported frequency of aneurysms varies from $4-12 \%$ after angioplasty in native adult CoA and is described in $5 \%$ of patients after previous surgical repair.(38) The lower incidence in patients after a previous surgical repair may be related to surgical scar tissue, which may protect against aneurysm and aortic dissection or rupture.

\section{Infective endocarditis or endarteritis}

Patients with native aortic CoA are predisposed to infective endocarditis or endarteritis due to an altered arterial wall structure, associated aortic and mitral valve anomalies with an abnormal blood flow and pressure, or persistent obstruction at the CoA site. Patients remain at risk, even after surgical or interventional treatment.

\section{Bicuspid aortic valve}

Up to $50 \%$ (-85\%) of patients with aortic CoA have a bicuspid aortic valve. ${ }^{(55)}$ Fibrosis, calcification, or myxomatous degeneration may lead to aortic valve stenosis and to aortic valve regurgitation, dilatation of the ascending aorta, which may progress to aortic aneurysms and even to aortic dissection and rupture. ${ }^{(56)}$ The complication rate of bicuspid aortic valves increases with age.

\section{Aneurysms of the Circle of Willis}

Berry aneurysms of the circle of Willis or other vessels occur in up to 10\% of patients with CoA. ${ }^{(57)}$ Aneurysm size and risk of rupture tend to increase with age and uncontrolled hypertension.

Many affected patients are asymptomatic until rupture occurs, although some aneurysms may leak prior to rupture and generate warning symptoms like headache, photophobia, weakness, or others.

As rupture of a cerebral aneurysm is associated with high mortality, specific treatment should be considered soon after diagnosis. Screening for cerebrovascular aneurysms should be promoted.

\section{Coronary artery disease}

As a result of the increased blood pressure the coronary arteries in CoA patients may develop premature narrowing or atherosclerosis, leading to coronary artery disease in early or mid-adulthood. Even in children after coarctation repair an increased intima media thickness as early sign of atherosclerosis could be detected. ${ }^{(13)}$ In the Mayo Clinic study of 1989, coronary artery disease was the most common cause of late postoperative death. ${ }^{(44)}$

\section{Thoracic musculoskeletal sequelae}

Elevation of the left shoulder, deviation of the scapula and/or scapula alata can often be recognized in adults after left posterolateral thoracotomy for aortic coarctation ${ }^{(58,59)}$ causing non-cardiac chest pain, presumably related to functional impairment of peripheral nerves supplying skeletal muscles (latissimus dorsi and serratus anterior muscles). ${ }^{(59)}$

\section{Precautions in Pregnancy}

Fortunately, after successful treatment of CoA many women tolerate pregnancy without major problems. Nevertheless, women with either native or treated aortic CoA have an increased risk during pregnancy due to the physiological hemodynamic and hormonal changes, particularly in the third trimester and in the peripartum period. ${ }^{(60)}$ Therefore, they need multidisciplinary monitoring throughout pregnancy.

At highest risk are women with unrepaired CoA, arterial hypertension, residual CoA. At particular risk of aortic rupture during pregnancy and delivery are women with aortic aneurysms due to coarctation. Maternal mortality due to aortic dissection ${ }^{(61)}$ and rupture of a cerebral aneurysm has been reported.

The recurrence risk of $\mathrm{COA}$ increases in the offspring of parents with CoA and with the number of affected relatives. The reported recurrence risk of $\mathrm{CoA}$ is about $2 \%$ if one sibling is affected and approximately $6 \%$ if two siblings are affected. ${ }^{(62)}$ Fetal echocardiography is mandatory early in pregnancy.

\section{LATE MANAGEMENT RECOMMENDATIONS FOR THE ADULT WITH COARCTATION}

CoA is a life-long disease and careful follow-up with serial assessment is required through infancy and adulthood to help prevent complications and to monitor for recurrences. ${ }^{(63)}$ Follow-up studies include a search for late complications, e.g. arterial hypertension, recurrent obstruction, aneurysm formation or other associated anomalies. Clinical examination alone is not sufficient and the use of modern imaging techniques is essential. 
Patients without residual obstruction who are normotensive at rest and with exercise can usually lead normally active lives without restriction, ${ }^{(64)}$ except for high-intensity static exercise on competition level. ${ }^{(64,65)}$ Patients with arterial hypertension, residual obstruction, or other complications should avoid heavy isometric exercises, in proportion to the severity of their problems.

The following patients may warrant surgical or percutaneous treatment:

All symptomatic patients with a $>20 \mathrm{mmHg}$ gradient across the coarctation.

Asymptomatic patients with a $>20 \mathrm{mmHg}$ gradient across the CoA and upper limb hypertension, pathologic blood pressure response during exercise, or significant left ventricular hypertrophy.

- Independent from the pressure gradient, some patients with $\geq 50 \%$ aortic narrowing (on MRI, CT or angiography).

Significant aortic valve stenosis or regurgitation.

Aneurysm of the ascending aorta.

Aneurysm at the previous CoA site.

Symptomatic or large aneurysms of the circle of Willis.

If treatment is necessary, it should occur in centers with extensive experience in the treatment of coarctation.

Surgical repair of re-CoA is demanding and associated with considerable morbidity, mortality (up to 20\%) and recurrence rates (up to 20\%). Even in experienced centers the mortality rate is $5-8 \%$.

The most important complications following re-operation or intervention include early paradoxical rebound hypertension, recoarctation, aneurysm formation, stroke, phrenic nerve and recurrent laryngeal nerve injury and paraplegia.

Until recently, lifelong endocarditis prophylaxis was recommended after surgical or interventional treatment of aortic coarctation. However, the use of endocarditis prophylaxis may change considerably, at least in the United States, due to recently published new recommendations. ${ }^{(66)}$

\section{REFERENCES:}

I. Marx GR. "Repaired" aortic coarctation in adults: not a "simple" congenital heart defect. J Am Coll Cardiol 2000;35: 1003-6.

2. Niwa K, Perloff JK, Bhuta SM, et al. Structural abnormalities of great arterial walls in congenital heart disease: light and electron microscopic analyses. Circulation 200।;103:393-400

3. Acierno L). The history of cardiology. Pearl River, NY: Parthenon Publishing Group Ltd., 1994.

4. Perloff JK. Clinical Recognition of Congenital Heart Disease. Philadelphia:W B Saunders Company, 2003.

5. Isner JM, Donaldson RF, Fulton D, Bhan I, Payne DD, Cleveland RJ. Cystic medial necrosis in coarctation of the aorta: a potential factor contributing to adverse consequences observed after percutaneous balloon angioplasty of coarctation sites. Circulation 1987;75:689-95.

6. Ong CM, Canter CE, Gutierrez FR, Sekarski DR, Goldring DR. Increased stiffness and persistent narrowing of the aorta after successful repair of coarctation of the aorta: relationship to left ventricular mass and blood pressure at rest and with exercise. Am Heart J 1992; 1 23:1594-600.

7. Vogt M, Kuhn A, Baumgartner D, et al. Impaired Elastic Properties of the Ascending Aorta in Newborns Before and Early After Successful Coarctation Repair: Proof of a Systemic Vascular Disease of the Prestenotic Arteries? Circulation 2005; I I 1:3269-73.

8. Brili S, Dernellis J, Aggeli C, et al. Aortic elastic properties in patients with repaired coarctation of aorta. Am J Cardiol 1998;82:1 | 40-3, a 10.

9. Vriend JW, de Groot E, Mulder BJ. Limited effect of early repair on carotid arterial wall stiffness in adult post-coarctectomy patients: in response to the article by Heger $M$, Willfort A, Neunteufl T, Rosenhek R, Gabriel H, Wollenek G, Wimmer M, Maurer G Baumgartner $\mathrm{H}$. Vascular dysfunction after coarctation repair is related to the age at surgery. Int J Cardiol 2004; in press. Int J Cardiol 2005; 100:335-6.

10. De Divitiis M, Pilla C, Kattenhorn M, et al.Vascular dysfunction after repair of coarctation of the aorta: Impact of Early Surgery. Circulation 200 I; 104: 1 651--70.

II. Vriend J], de Groot E, Kastelein Jj, Mulder BJ. Carotid and femoral B-mode ultrasound intima-media thickness measurements in adult post-coarctectomy patients. Int Angiol 2004;23:41-6.

12. Vriend JW, Zwinderman AH, de Groot E, Kastelein J], Bouma BJ, Mulder BJ. Predictive value of mild, residual descending aortic narrowing for blood pressure and vascular damage in patients after repair of aortic coarctation. Eur Heart J 2005;26:84-90.

13. Meyer AA, Joharchi MS, Kundt G, Schuff-Werner P, Steinhoff G, KienastW. Predicting the risk of early atherosclerotic disease development in children after repair of aortic coarctation. Eur Heart J 2005;26:617-22.

14. De Divitiis M, Pilla C, Kattenhorn M, et al. Ambulatory blood pressure, left ventricular mass, and conduit artery function late after successful repair of coarctation of the aorta. J Am Coll Cardiol 2003;41:2259-65.

15. Gardiner HM, Celermajer DS, Sorensen KE, et al. Arterial reactivity is significantly impaired in normotensive young adults after successful repair of aortic coarctation in childhood. Circulation 1994;89:1745-50.

16. Samanek M, Voriskova M. Congenital heart disease among 8|5,569 children born between 1980 and 1990 and their 15-year survival: a prospective Bohemia survival study. Pediatr Cardiol 1999;20:41 I-7.

17. Subramanian J, Kinare SG. Coarctation of aorta. J Postgrad Med 1983;29:1-6.

18. Ongley PA. Pediatric cardiology in Thailand. Circulation 1966;34: I-3.

19. McBride KL, Pignatelli R, Lewin M, et al. Inheritance analysis of congenital left ventricular outflow tract obstruction malformations: Segregation, multiplex relative risk, and heritability. Am J Med Genet A 2005; 1 34:180-6.

20. Wessels MW, Berger RM, Frohn-Mulder IM, et al. Autosomal dominant inheritance of left ventricular outflow tract obstruction. Am J Med Genet A 2005; 134:171-9.

21. Campbell M. Natural history of coarctation of the aorta. Br Heart | 1970;32:633-40.

22. Perloff JK. Congenital Heart Disease in Adults. Philadelphia: W B Saunders Company, 1998.

23. Connelly MS, Webb GD, Somerville J, et al. Canadian Consensus Conference on Adult Congenital Heart Disease 1996. Can J Cardiol 1998; 14:395-452.

24. Aboulhosn J. Child JS. Left ventricular outflow obstruction: subaortic stenosis, bicuspid aortic valve, supravalvar aortic stenosis, and coarctation of the aorta. Circulation 2006; | |4:2412-22 
25. Valdes-Cruz LM, Cayre RO. Echocardiographic Diagnosis Of Congenital Heart Disease: An Embryologic And Anatomic Approach. Philadelphia, PA: Lippincott Williams \& Wilkins, 1998

26. Lim DS, Ralston MA. Echocardiographic indices of Doppler flow patterns compared with MRI or angiographic measurements to detect significant coarctation of the aorta. Echocardiography 2002; 19:55-60.

27. Kaemmerer H, Stern H, Fratz S, Prokop M, Schwaiger M, Hess J. Imaging in adults with congenital cardiac disease (ACCD). Thorac Cardiovasc Surg 2000;48:328-35

28. O'Laughlin MP, Perry SB, Lock JE, Mullins CE. Use of endovascular stents in congenita heart disease. Circulation 1991;83:1923-39.

29. Rao PS. Stents in the management of congenital heart disease in pediatric and adult patients. Indian Heart | 200 |:53:7|4-30.

30. Rao PS. Coarctation of the aorta. Curr Cardiol Rep 2005;7:425-34

31. Chessa M, Carrozza M, Butera G, et al. Results and mid-long-term follow-up of stent implantation for native and recurrent coarctation of the aorta. Eur Heart 2005;26:2728-32.

32. Shah L, Hijazi Z, Sandhu S, Joseph A, Cao QL. Use of endovascular stents for the treatment of coarctation of the aorta in children and adults: immediate and midterm results. J Invasive Cardiol 2005; 17:614-8

33. Lababidi Z, Madigan N, Wu JR, Murphy TJ. Balloon coarctation angioplasty in an adult. Am J Cardiol 1984;53:350- I.

34. Blalock A, Park EA. Surgical treatment of experimental coarctation (atresia) of aorta. Ann Surg 1944; 1 19:445-56.

35. Gross RE, Hufnagel CA. Coarctation of the aorta: experimental studies regarding its surgical correction. N Engl J Med 1945;233:287-93.

36. Crafoord C, Nylin G. Congenital coarctation of the aorta and its surgical treatment JThorac Surg 1945; | 4:347-61.

37. Kouchoukos NT, Laks H, Wechsler AS. Advances in Cardiovascular Surgery: Mosby, 1989.

38. Rothman A. Coarctation of the aorta: an update. Curr Probl Pediatr 1998;28:33-60

39. Cowley CG, Orsmond GS, Feola P, McQuillan L, Shaddy RE. Long-term, randomized comparison of balloon angioplasty and surgery for native coarctation of the aorta in childhood. Circulation 2005; 1 । 1:3453-6.

40. Leenen FH, Balfe JA, Pelech AN, Barker GA, Balfe JW, Olley PM. Postoperative hypertension after repair of coarctation of aorta in children: protective effect of propranolol? Am Heart J 1987; I I 3: I 164-73.

41. Gidding SS, Rocchini AP, Beekman R, et al. Therapeutic effect of propranolol on paradoxical hypertension after repair of coarctation of the aorta. $N$ Engl J Med 1985;312:1224-8.

42. Toro-Salazar OH, Steinberger J, Thomas W, Rocchini AP, Carpenter B, Moller JH. Long term follow-up of patients after coarctation of the aorta repair. Am J Cardiol 2002;89:541-7.

43. Presbitero P,Demarie D,Villani M, et al. Long term results ( $15-30$ years) of surgical repair of aortic coarctation. Br Heart J 1987:57:462-7.

44. Cohen M, FusterV, Steele PM, Driscoll D, McGoon DC. Coarctation of the aorta. Long term follow-up and prediction of outcome after surgical correction [see comments]. Circulation 1989:80:840-5.

45. Diller GP, Dimopoulos K, Okonko D, et al. Exercise intolerance in adult congenital heart disease: comparative severity, correlates, and prognostic implication. Circulation 2005; | | 2:828-35.

46. O'Sullivan J], Derrick G, Darnell R. Prevalence of hypertension in children after early repair of coarctation of the aorta: a cohort study using casual and 24 hour blood pressure measurement. Heart 2002;88: 163-6.

47. Hauser M, Kuehn A, Wilson N. Abnormal responses for blood pressure in children and adults with surgically corrected aortic coarctation. Cardiol Young 2000; 1 0:353-7.

48. Hager A, Kanz S, Kaemmerer H, Schreiber C, Hess J. Coarctation Long-term Assessment (COALA): Significance of arterial hypertension in a cohort of 404 patients up to 27 years after surgical repair of isolated coarctation of the aorta, even in the absence of restenosis and prosthetic material.The Journal of Thoracic and Cardiovascular Surgery 2007:134:738-45.e2
49. Kaemmerer H, Oelert F, Bahlmann J, Blucher S, Meyer GP, Mugge A.Arterial hypertension in adults after surgical treatment of aortic coarctation. Thorac Cardiovasc Surg 1998:46:121-5.

50. Swan L, Goyal S, Hsia C, Hechter S, Webb G, Gatzoulis MA. Exercise systolic blood pressures are of questionable value in the assessment of the adult with a previous coarctation repair. Heart 2003;89: I 89-92

5।. Bouchart F, Dubar A, Tabley A, et al. Coarctation of the aorta in adults: surgical results and long-term follow-up. Ann Thorac Surg 2000;70: I 483-8; discussion 8-9.

52. Pinzon JL, Burrows PE, Benson LN, et al. Repair of coarctation of the aorta in children: postoperative morphology. Radiology 1991;180:199-203.

53. Yetman AT, Nykanen D, McCrindle BW, et al. Balloon angioplasty of recurrent coarctation: a 12-year review. J Am Coll Cardiol 1997;30:8। I-6.

54. Von Kodolitsch Y,Aydin MA, Koschyk DH, et al. Predictors of aneurysmal formation after surgical correction of aortic coarctation. J Am Coll Cardiol 2002;39:617-24.

55. Roos-Hesselink JW, Scholzel BE, Heijdra RJ, et al. Aortic valve and aortic arch pathology after coarctation repair. Heart 2003;89:1074-7.

56. Sabet HY, Edwards WD, Tazelaar HD, Daly RC. Congenitally bicuspid aortic valves: a surgical pathology study of 542 cases (1991 through 1996) and a literature review of 2,715 additional cases. Mayo Clin Proc 1999;74:14-26.

57. Connolly HM, Huston J, 3rd, Brown RD, Jr.,Warnes CA, Ammash NM, TajikAJ. Intracranial aneurysms in patients with coarctation of the aorta: a prospective magnetic resonance angiographic study of 100 patients. Mayo Clin Proc 2003;78: | 49|-9.

58. Kaemmerer H. Magnetresonanztomographische Untersuchungen an Adoleszenten und Erwachsenen mit angeborenen herzfehlern zur Erfassung von Rest- und Folgezuständen nach interventioneller Behandlung oder operativer Korrektur. Zentrum für Innere Medizin und Dermatologie Abteilung für Kardiologie. Mannover: Medizinische Hochschule Hannover, 1993:203.

59. Emmel M, Ulbach P, Herse B, et al. Neurogenic lesions after posterolateral thoracotomy in young children. Thorac Cardiovasc Surg 1996;44:86-91.

60. Beauchesne LM, Connolly HM, Ammash NM, Warnes CA. Coarctation of the aorta: outcome of pregnancy. J Am Coll Cardiol 200 I;38: 1728-33.

61. Hager A, Kaemmerer H, Hess J. Comment on pregnancy and aortic root growth in the Marfan syndrome. Eur Heart J 2005;26:2346.

62. Nora J], Nora AH. Maternal transmission of congenital heart diseases: new recurrence risk figures and the questions of cytoplasmic inheritance and vulnerability to teratogens. Am J Cardiol 1987;59:459-63.

63. Stewart AB, Ahmed R, Travill CM, Newman CG. Coarctation of the aorta life and health 20-44 years after surgical repair. Br Heart J 1993;69:65-70

64. Pelliccia A, Fagard R, Bjornstad HH, et al. Recommendations for competitive sports participation in athletes with cardiovascular disease: a consensus document from the Study Group of Sports Cardiology of the Working Group of Cardiac Rehabilitation and Exercise Physiology and the Working Group of Myocardial and Pericardial Diseases of the European Society of Cardiology. Eur Heart J 2005;26: I 422-45.

65. Graham J, Thomas P, Driscoll DJ, Gersony WM, Newburger JW, Rocchini A, Towbin JA. 36th Bethesda conference: recommendations for determining eligibility for competition in athletes with cardiovascular abnormalities. Task Force 2: Congenital heart disease. J Am Coll Cardiol 2005;45: 1326-33

66. Wilson W, Taubert KA, Gewitz M, et al. Prevention of infective endocarditis: guidelines from the American Heart Association: a guideline from the American Heart Association Rheumatic Fever, Endocarditis, and Kawasaki Disease Committee, Council on Cardiovascular Disease in the Young, and the Council on Clinical Cardiology, Council on Cardiovascular Surgery and Anesthesia, and the Quality of Care and Outcomes Research Interdisciplinary Working Group. Circulation 2007;1 I 6:1736-54. 